Kwong, Jack. (2015). Open-Mindedness as a Critical Virtue. Topio. The final publication is available at Springer via DOI: 10.1007/s11245-015-9317-4. ISSN: 0167-7411 (Print) 1572-8749 (Online)

\title{
Open-Mindedness as a Critical Virtue
}

\author{
Jack M. C. Kwong
}

\begin{abstract}
This paper proposes to examine Daniel Cohen's recent attempt to apply virtues to argumentation theory, with special attention given to his explication of how open-mindedness can be regarded as an argumentational or critical virtue. It is argued that his analysis involves a contentious claim about open-mindedness as an epistemic virtue, which generates a tension for agents who are simultaneously both an arguer and a knower (or who strive to be both). I contend that this tension can be eased or resolved by clarifying the nature of open-mindedness and by construing open-mindedness in terms of its function. Specifically, a willingness to take a novel viewpoint seriously is sufficient for making open-mindedness both an epistemic and a critical virtue.
\end{abstract}

Keywords Argumentation theory · Virtues · Open-mindedness · Daniel Cohen · Epistemic virtue . Critical virtue

\section{Introduction}

In this paper, I examine Daniel Cohen's recent attempt to apply a virtue-based approach to argumentation theory, focusing on his analysis of open-mindedness as a critical or argumentational virtue (Cohen 2009). ${ }^{1}$ Although Cohen's conclusion that an arguer should cultivate open-mindedness as a critical virtue is well-taken, his analysis poses a problem for agents who are both an arguer and a knower, or who strive to be both. My assessment is that Cohen's argument hinges on a contentious claim about open-mindedness as an epistemic virtue. To resolve this problem, I argue that we need to clarify the nature of open-mindedness. I do this by examining recent accounts of openmindedness in virtue epistemology, and proposing a functional view that demonstrates how open-mindedness can be both a critical and an epistemic virtue. While the main focus of this paper is to address Cohen's analysis, it serves at the same time to examine the character trait of openmindedness, and to illustrate how a virtue can take on different statuses (i.e., intellectual, epistemic, and argumentational).

A word is fitting at this point to spell out some of the underlying assumptions in this study. This paper accepts that the 'aretaic turn' as it applies to argumentational theory is a viable project, and that such a turn offers promising insights into questions that currently beset the subject (e.g., Aberdein 2010, 2014; Cohen 2005, 2009). Also, it takes for granted that it is permissible to apply the virtues at the level of arguers (as opposed to arguments, though it does not rule out that there might be virtues that are also applicable to the latter). For instance, appealing to virtues to distinguish good arguers from bad ones does not commit the fallacy of ad hominem, at least not in a vicious way (see Aberdein 2010, 2014). Lastly, following Aberdein and Cohen, this paper also construes 'arguer' broadly to refer not only to the person doing the arguing, but also to anyone who responds, participates, or observes in the course of the argument (Cohen 2009; Aberdein 2010).

\footnotetext{
${ }^{1}$ In this paper, I will use the terms 'critical' and 'argumentational' interchangeably.
} 


\section{The Tension}

Let us begin with some general remarks about openmindedness. Although the application of virtues to argumentation theory makes no claim to what Guy Axtell calls virtue reliabilist or virtue responsibilist epistemologies, the discussion below will assume both the latter to be the working premises (Axtell 1997). Open-mindedness as construed here is a character trait, as opposed to a subpersonal cognitive state or faculty, which the agent is involved in or makes an effort at cultivating and exercising. Moreover, her involvement helps to bring about some cognitive goods or enables her to reach various cognitive achievements. If the agent's exercise of open-mindedness is motivated, for example, by getting to the truth or achieving knowledge, then the virtue to be attained is regarded as an epistemic one (e.g., Baehr 2011; Riggs 2010). ${ }^{2}$ By contrast, if her exercise is "an expression out of moral concern", that is, with what is right or wrong, then the end virtue is viewed as a moral one (e.g., Arpaly 2011). In either instance, given the agent's involvement, she can be credited for cultivating and exercising open-mindedness. Depending on whether she exercises it as a moral and/ or intellectual virtue, her personal moral and/or intellectual worth may also proportionately increase (Baehr 2012).

According to Cohen, open-mindedness can also be regarded as a critical or argumentational virtue. In his view, argumentational virtues are "aids on the way to achievements in argumentation" (Cohen 2009, 54) and "can be defined by the [cognitive] goods that they help us procure and by the accomplishments that they help us achieve in the course of argumentation" (55). Such goods include those derivable from the three standard branches of argumentation, namely, valid argument in logic, rational persuasion in rhetoric, and "critically achieved consensus" in dialectic. They also comprise those that can be brought about by argument but which do not "fit neatly into" the above three categories (ibid.). Here is Cohen's list:

- a deepened understanding of one's own position;

- improvement of one's position;

- abandonment of a standpoint for a better one, other than the opponent's;

- a deepened understanding of an opponent's position;

- acknowledgement of (the reasonableness of) another's position;

\footnotetext{
${ }^{2}$ Cohen distinguishes intellectual (or cognitive) virtues from epistemic ones. For him, the latter are concerned principally with the acquisition of true belief and knowledge, whereas the former incorporate a wider range of goods (e.g., understanding, discharging our responsibilities as arguers). While many virtue epistemologists refer to open-mindedness as an intellectual virtue, they are essentially referring to it as an epistemic virtue in Cohen's sense. Unless otherwise noted, this paper will follow Cohen's usage.
}

- greater attention to previously over-looked or undervalued details;

- better grasp of connections and how things might be fit together in a big picture (ibid., his italics).

Why should we think of open-mindedness as a critical or argumentational virtue? Regarding the nature of the character trait of open-mindedness, Cohen does not spend much time on elucidating it, relying instead, for the most part, on a standard definition used in critical thinking and on the usage of the term in a debate in the philosophy of education (e.g., Hare 1985a, b; Hare and McLaughlin 1998; Gardner 1996; McLaughlin 1990). Accordingly, open-mindedness as Cohen understands it consists of "the ability to listen carefully, the willingness to take what others say seriously, and if called for, the resolve to adopt them as one's own" (Cohen 2009, 56). To this description, he adds a complementary component: open-mindedness also includes the "willingness, ability, and resolve to re-examine one's own beliefs and, if called for, to let them go. Belief revision is not just a matter of belief-acquisition; it also involves belief modification and even belief rejection" (ibid., his underline).

The reason Cohen thinks that open-mindedness is a critical virtue is that the intellectual activities associated with the character trait facilitate the realization of the cognitive goods identified above. To get a deepened understanding of an opponent's position, for instance, the arguer cannot simply go through the motions by listening to it. If there is no real possibility that the arguer can change her mind after hearing her opponent out-a possibility that is brought about only if she is open-mindedthen the arguer does not gain anything from the argument. Given that open-mindedness is instrumental to the successful attainment of these goods, it is therefore deemed an argumentational virtue. Moreover, since keeping an open mind can help bring about such a wide range of cognitive goods, Cohen concludes that "[w]hen it comes [to] our more general cognitive and critical projects, open-mindedness seems to be valuable across the board" (ibid.).

To highlight this point about the value of open-mindedness as an "almost uniformly" cognitive virtue (56-57), Cohen contrasts it with the value of the character trait as an epistemic virtue. As mentioned above, what makes a virtue the kind of virtue that it is (i.e., epistemic, moral or critical) depends on the kinds of goods that one hopes to gain from exercising it. In this case, what makes open-mindedness an epistemic virtue is that an agent's being open-minded is supposed to increase one's chances of achieving knowledge or getting to the truth. Thus, if a person is willing to take what others say seriously under the right circumstances, she stands a better chance of getting to the truth and acquiring knowledge. But not all circumstances, 
according to Cohen, are right. As he notes, open-mindedness "is not always or necessarily an epistemic virtue" (57). Indeed, Aberdein even goes so far as to characterize Cohen's position as saying that open-mindedness is an epistemic vice (Aberdein 2010, 174).

Consider someone whose beliefs are mostly true. Would such a person stand to gain anything from being openminded? Cohen does not think so: "simply allowing that [our strongly held beliefs] be up for discussion calls them into question - and calling beliefs into question, even ones that are well-justified, runs the risk of losing them" (Cohen 2009,57 ). If the ultimate goal for being open-minded is to get to the truth, then we should not be open-minded when a cherished truth might be at stake. Indeed, Cohen claims that open-mindedness "is most important for people whose beliefs are mostly unjustified or wrong" (ibid.). Openmindedness, therefore, is not necessarily an epistemic virtue for everyone under all circumstances; its value as an epistemic virtue is circumscribed and localized. But if open-mindedness has such a restricted application, what explains our intuition that cultivating such a character trait is generally a good thing? Or as Cohen puts it, isn't it “a priori that being open-minded is intellectually more virtuous than being closed-minded" (59)? Here is where openmindedness as a critical virtue enters the picture. According to Cohen, "there is more to open-mindedness than its role in epistemic pursuits" (ibid). As noted above, it also plays a significant role in argumentational contexts, specifically by helping us reap the aforementioned nonepistemic cognitive goods on Cohen's list. These extraepistemic pursuits, then, are what make open-mindedness almost always a cognitive virtue.

To summarize, Cohen makes two claims: (1) when open-mindedness is exercised with the aim of reaping nonepistemic cognitive goods from argument, it is a virtue "across the board"; and (2) when open-mindedness is exercised in a context related to the pursuit of knowledge, it is not always or necessarily an epistemic virtue. In my view, these two claims, when taken collectively, cause an uneasiness with respect to our status as intellectual agents, that is, as agents with epistemic, argumentational and other cognitive interests. If an agent is arguing with an opponent in a context in which her cognitive goals are completely severed from the pursuit of knowledge-e.g., she hopes to catch the nuances of her opponent's views that she has glossed over before-then by (1), she should exercise open-mindedness so as to reap the non-epistemic cognitive goods. And if an agent argues in a context in which her central aim is the acquisition of knowledge-e.g., if one of her cherished beliefs is challenged - then by (2), she should exercise caution in being open-minded for fear of losing her beliefs, or ending up in a weaker epistemic position.
A tension arises, I contend, when we acknowledge that there are very few scenarios in which we are just arguing or just pursuing knowledge. In many cases, I submit that we are doing both simultaneously, which makes us at once both arguers and knowers. For instance, we typically argue with others over issues that we care about, have a stake in, or want to learn more about, with the hope to uncover truths or to acquire knowledge. However, given Cohen's claims about the different statuses of open-mindedness as a virtue, we find ourselves in a predicament: When we are not merely arguing or merely pursuing knowledge, but are doing both, should we strive to be open-minded?

The answer, it would seem, is 'no'. Many of the cognitive gains of open-mindedness on Cohen's list-for instance, a deepened understanding of an opponent's position and an acknowledgement of another's reasonablenesswhile non-epistemic in nature, require that we treat an opponent's views seriously. But as Jonathan Adler has pointed out, this seems to require that we entertain the possibility that these views are true, and by implication, that one's own views might be mistaken (Adler 2004). For instance, suppose I am a hardcore physicalist about mental states and I am arguing with someone who is a substance dualist. If one of my goals is to understand my opponent's position or to acknowledge its reasonableness, I will have to put myself "in her shoes" to see the merits of her view. If Adler is correct, then my entertaining an opponent's view seriously - that is, my exercising an open mind-even though it is done under the pursuit of the stated non-epistemic cognitive goals, runs the risk noted above: I am placing my beliefs on the table and may end up losing them. In other words, some of the cognitive goods on Cohen's list turn out to be not completely free from epistemic pursuits. Indeed, Cohen acknowledges this possibility of the argumentational preempting the epistemic when he makes the case for the importance of open-mindedness as an argumentational virtue by contrasting it with one's failure to exhibit it. According to Cohen, someone who fails to be open-minded closes the door on the possibility of "actually revising one's standpoint as a result of listening to objections" (2009, 59). But why worry about revising one's standpoint if all one is doing falls strictly under the argumentational? I contend that it is because the attainment of some of the cognitive goods on Cohen's list requires us to engage in activities that have epistemic consequences, most notably, by putting our beliefs on the table.

Here is an alternative way to capture this tension. Intuitively, it seems plausible for someone to strive to be both a good arguer and a good knower. But this aspiration seems to be blocked by Cohen's two claims discussed above. Again, if an agent wants to be just a good arguer with no regard for truth and knowledge, she will, among other 
things, aim to be open-minded toward her opponent's views so as to reap the cognitive gains on Cohen's list. And if an agent wants to be just a good knower, she will refrain from being open-minded at least with respect to beliefs that she holds closely. ${ }^{3}$ But what happens if she wants to be both a good arguer and a good knower? Should or shouldn't she be open-minded? Perhaps we can answer this once we work out the details of the nature and importance of the beliefs or standpoints involved, weigh the pros and cons in terms of the goods to be gained or lost, and so on (more on this point below). Suffice it to note now that Cohen's dual claims cause a tension that would not otherwise arise when one aims to be good in both activities of arguing and knowing.

What my argument so far shows is that while there are argumentational activities that are not epistemic or do not stem from epistemic concerns, they nevertheless are inextricably linked to the pursuit of knowledge. Conducting these activities potentially places our beliefs on the table and therefore, puts us at risk of losing them. Insofar as we are simultaneously arguers and knowers, and as such, incur both argumentational and epistemic obligations, we must exercise caution in being open-minded, in the interest of preserving our true beliefs. An important implication of this epistemic constraint is that in practice the value of open-mindedness as a cognitive virtue may be just as local and "dependent on context and situation" as that of openmindedness as an epistemic virtue (Cohen 2009, 58). At the minimum, any cognitive gain on Cohen's list that results in one's beliefs being confronted or "put on the table," so to speak, must be eliminated. Indeed, I think a further argument can be made to show that every cognitive gain on his list runs the risk of requiring an agent to abandon her true beliefs. In arguing with an opponent, an agent can easily fail to accomplish what she sets out to do. For example, she may want to get a deepened understanding of her own position through arguing with an opponent, but may realize in the process or afterwards that she never fully understood it in the first place, thus causing her either to abandon it or to approach it with a weakened confidence. ${ }^{4}$ Similarly, an agent may be too successful in acknowledging the reasonableness of another's position: after argument, she may realize that the alternative position is not only reasonable but also more plausible than her own. Again, such a

\footnotetext{
3 Incidentally, as Riggs has pointed out, it is precisely with respect to beliefs that we hold closely that we should exercise open-mindedness (177). This is because many of them-e.g., political and religious ones-may have been acquired dubiously (i.e., through biases and/or cognitive weaknesses or blind-spots).

4 The agent's discovery that she does not have as good an understanding of her original view does not necessarily imply that her view is false. She may, for example, simply have trouble grasping some of its more difficult components.
}

realization takes place only if she is open-minded, as it can cause her to give up her original view. Whether an argument can be made for or against the remaining gains on the list is an issue I will not explore here. Suffice it to note now that Cohen's claims (1) and (2) jointly threaten to make open-mindedness as a cognitive virtue just as contingent, or in Cohen's words, "locally" useful, as open-mindedness is as an epistemic virtue.

At this point, I would like to pause and consider an objection that may be raised against my argument. ${ }^{5}$ So far, I have assumed that whenever epistemic obligations or considerations are pitted against argumentational ones, the former always trump or nullify the latter. Thus, if being open-minded involves engaging in certain cognitive activities that unnecessarily open up our true beliefs for questioning with the promise only of gain of certain nonepistemic cognitive goods, I have suggested that we ought not pursue them; otherwise, we would be violating our epistemic obligations of preserving our true beliefs and knowledge. But why must epistemic considerations always trump the argumentational? Could not the prospect of reaping some of the cognitive goods on Cohen's list override the risk of losing one's true beliefs?

There are, in my view, two ways in which we can respond to this objection. The first is to furnish an explanation as to why epistemic considerations should trump argumentational ones. One way to do so is to point out how argumentational virtues relate to epistemic ones. According to Aberdein, whereas epistemic virtues track truth and moral virtues track the good, argumentational virtues propagate truths $(2010,173)$. This way of thinking about what the virtues of an ideal arguer track, Aberdein notes, is consistent with all of the cognitive goals on Cohen's list. What it means for these virtues to propagate truth, in his view, is that virtuous arguments "should provide interlocutors and audience with new true beliefs, or at least reasons to increase the confidence with which they hold to existing true beliefs" (ibid.). Similarly, the "outcome of an argument between virtuous arguers would be a wider distribution of true beliefs" (ibid.) For Aberdein, then, the difference between a virtuous knower and a virtuous arguer is that the former is "disposed to act in a way that leads to the acquisition of true beliefs", while the latter is "disposed to spread true beliefs around" (ibid., my italics). ${ }^{6}$

\footnotetext{
5 I would like to thank an anonymous referee for raising this objection.

${ }^{6}$ In my view, Aberdein's claims confirm my earlier point regarding the close ties between the argumentational and the epistemic in terms of truth: arguing is a means by which to change the epistemic status of another (including one's own). Indeed, notice that an agent's firmly held beliefs, which, according to Cohen, should allow no room for open-mindedness, are ready information for her to relay to others. But when she tries to do so, to repeat an earlier point, she may fall short of
} 
Notice that if Aberdein is correct, then this gives us reason for favoring the epistemic over the argumentational when a tension exists between them: Insofar as the function of argumentational virtues is supposed to propagate truths, any intellectual activity that runs counter to this function, e.g., by unnecessarily calling these true beliefs into question and causing their potential loss, must be exercised with caution or altogether avoided. Otherwise, the open-minded arguer, far from spreading true beliefs, may be instilling false ones in others and reinforcing these for herself.

The second way to respond to the objection is to concede that there may well be cognitive goods on Cohen's list that justify the epistemic risk of losing true beliefs or knowledge. In response to the earlier query as to whether we, qua arguers and knowers, should exercise openmindedness, the answer is now "yes". Such a concession, however, does little to allay worries about the initial tension with respect to Cohen's dual claims. Agents who are simultaneously arguers and knowers (or who strive to be good at both) would still find themselves in conflict in deciding to be open-minded. Although they may now reap certain non-epistemic cognitive goods by being openminded, and thus bolster their status as good arguers, they do so at the expense of failing to meet their epistemic obligations (i.e., losing previously held beliefs), and thus jeopardize their status as good knowers. In short, they would remain troubled by their status as intellectual agents motivated by epistemic, argumentational and other cognitive interests.

Let us take stock of the argument so far. To clarify, the present argument does not challenge Cohen's contention that there are non-epistemic cognitive goods that can be obtained from exercising open-mindedness. Indeed, I agree with him that this observation furnishes strong grounds for positing open-mindedness as an argumentational virtue. However, some of these non-epistemic cognitive goods require that we engage in activities that have epistemic consequences, such as placing our beliefs on the table and running the risk of losing them. Now, this is unproblematic if our intellectual aspirations are such that we want only to be good arguers, and therefore, are only bound by argumentational obligations. But as I noted above, we seldom are simply arguers with no concern for truth or knowledge.

\footnotetext{
Footnote 6 continued

the task: she may encounter objections that she discovers she cannot answer. This of course does not necessarily imply that her beliefs are false, but it does put her at an epistemic risk. In such a case, not only will she fail to disseminate what to her are true beliefs, but she will also have to revise her own epistemic position: either to abandon those beliefs or to reduce her confidence in them. At any rate, the agent's exercise of open-mindedness, although done with the intent to bring about certain non-epistemic cognitive goals (i.e., to make her beliefs accessible to others), results, directly or indirectly, in exposing the weaknesses of her beliefs and even in losing them.
}

In most contexts, we also are knowers with obligations to preserve our true beliefs and to acquire knowledge. Given these latter obligations, we cannot therefore regard openmindedness as a cognitive virtue in practice as valuable across the board.

Insofar as the tension identified in Cohen's argument arises from his two claims about open-mindedness, it can be resolved by rejecting one or both of these claims. As mentioned at the outset, I support Cohen's contention that open-mindedness deserves to be treated as a critical virtue. I am also inclined to agree with him that it is "a priori that being open-minded is intellectually more virtuous than being close-minded" $(2009,59)$. In the next section, I propose to make good the claim that open-mindedness as an intellectual virtue is at once an epistemic and argumentational virtue. My way out of the tension in Cohen's argument is to reject his claim that open-mindedness is not always necessarily an epistemic virtue. ${ }^{7}$ To do so, we need to reconsider the nature and definition of open-mindedness as a character trait.

\section{Rethinking Open-Mindedness}

As noted earlier, Cohen does not say much about the nature of open-mindedness; instead, he relies on a textbook definition and on usage by some theorists in the philosophy of education: the former explains open-mindedness as "the ability to listen carefully, the willingness to take what others say seriously, and, if called for, the resolve to adopt them as one's own", and the latter, as advanced by William Hare, points to "the willingness to entertain objections and, if appropriate, revise one's position" (Cohen 2009, 56). However, as some theorists have observed (e.g., Baehr 2011; Riggs 2010), these definitions are problematic because they are too broad, encompassing intellectual activities that are not distinctive to open-mindedness. According to them, an important desideratum for theorizing about intellectual virtues is that we have to explain why a virtue is an intellectual virtue but also why it is that particular intellectual virtue. Put another way, we have to explain why it deserves the status as an intellectual virtue, and how it is distinct from other traits that might also be regarded as intellectual virtues. As Riggs has argued, the problem with the foregoing definitions (and he specifically has Hare's in mind) is that they construe open-mindedness so comprehensively that "it seems nothing short of rationality itself", and that they seem "to virtually equate being open-minded with being intellectually virtuous tout court" (Riggs, 179). As he notes, "if someone

\footnotetext{
$\overline{7}$ Indeed, most virtue epistemologists already think of open-mindedness as an epistemic virtue, and regard it as one of the most important ones (Baehr 2011; Riggs 2010).
} 
is 'disposed to revise or reject the position he holds if sound objections are brought against it, or... make up his mind in the light of available evidence as objectively and impartially as possible,' what is left to say about the quality of his reasoning? (Hare 1979, 9)" (ibid.).

Here, I leave it open as to whether Cohen fully subscribes to Hare's view of open-mindedness (and thus, the extent to which the above criticism applies to him); indeed, one gets the impression that Cohen's main concern has less to do with what it means for someone to be open-minded, which he takes to be generally unproblematic and wellunderstood, than with whether its status as a virtue can extend beyond the epistemic (i.e., to the argumentational). Nevertheless, I think we can adapt Riggs's criticism to take issue with Cohen's claim that open-mindedness is not necessarily an epistemic virtue. Recall Cohen's argument for it: "[S]imply allowing that [our beliefs] be up for discussion calls them into question-and calling beliefs into question, even ones that are well-justified, runs the risk of losing them" (2009, 57). Similarly, he observes that for people "whose beliefs are mostly in order", open-mindedness "is epistemologically risky, unnecessary, and unwise. It will lead away from justified beliefs" (ibid.).

In my view, Cohen's attribution of this unwelcome epistemic consequence to open-mindedness is questionable. While being open-minded may lead to a loss of justified beliefs, it may also lead to other outcomes such as steadfastness in the face of the challenge or even acquiring, in its wake, a strengthened confidence in held beliefs. Indeed, if all we are told is that an agent is open-minded, we cannot even speculate on the likelihood of any of these possibilities. What this establishes is that open-mindedness (or putting one's beliefs on the table) is not only compatible with either the loss or retention of one's beliefs, but also, more importantly, is neutral in the determination of the outcome. Rather, what is directly responsible for the outcome, I contend, are other intellectual activities that take place once the agent exercises open-mindedness. ${ }^{8}$ Thus, when an agent loses her justified beliefs, such a consequence may be due to her inadequate skills (e.g., her incompetency at certain tasks), or faulty cognitive abilities and faculties (e.g., a faulty memory or proneness to mistakes when making logical inferences). It can also be due to her possession of negative character traits, such as the

\footnotetext{
${ }^{8}$ It is beyond the scope of this paper to go into detail about what an agent might do once she puts a belief on the table. However, I find it instructive to think of it in terms of what Robert Brandom calls the 'game of giving and asking for reasons', a discursive practice in which the commitments and entitlements of an agent and her interlocutors are made explicit and defended (Brandom 1994). Here, we can imagine numerous ways in which an agent might exhibit failings that can cause her to abandon her beliefs (e.g., the discovery that she is not entitled to a particular view, or that her current position commits her to unwanted consequences).
}

intellectual vices of carelessness, inattentiveness, laziness, and impatience. Any or any combination of these, which have little to do with being open-minded, can occur once the agent calls her beliefs into question. Moreover, any or any combination of these, I submit, is sufficient for causing the agent to lose a true belief or to replace it with a false one. In short, once we properly circumscribe the role of open-mindedness, minimally by recognizing that it is compatible with either the loss or retention of beliefs, then we see that the risk of losing true beliefs lies elsewhere in other intellectual operations. Contrary to Cohen, then, open-mindedness is not the culprit for an agent's losing her justified beliefs.

Another argument that we can make against Cohen is that his argument conflates the following claims about open-mindedness: (a) open-mindedness is not necessarily an epistemic virtue; and (b) open-mindedness is an epistemic virtue but ought not to be applied all of the time. One of the reasons he offers for (a) is that the value of openmindedness is dependent on context and situation. For instance, he claims that the "willingness to entertain everything entails entertaining such possible defeaters for justification as dreams and evil demons and alternative conceptual schemes". Skepticism will result, leading to "a complete loss of knowledge and a disastrous end to that epistemic project" $(2009,58)$. But what this shows is not that open-mindedness is not an epistemic virtue but only that it ought not to be applied all of the time. Indeed, those who argue that open-mindedness is an important epistemic virtue specify conditions under which we exercise it. For example, Baehr argues that "a person S's engaging in the activity characteristic of open-mindedness under circumstances $\mathrm{C}$ is intellectually virtuous only if it is reasonable for $\mathrm{S}$ to believe that engaging in this activity in $\mathrm{C}$ may be helpful for reaching the truth" $(2011,210)$. By this criterion, Baehr may prescribe that an agent can refuse to entertain the aforementioned defeaters if doing so does not bring her closer to the truth. The important point to note, however, is that Baehr argues this while maintaining that open-mindedness is an epistemic virtue. Similarly, Riggs submits that "an open-minded person need not take all challenges to her beliefs seriously. Moreover, such a person can decline such a challenge regarding $p$ while being openminded about $p$ " (186, his italics). For our purposes, it is not necessary to go into detail about the conditions under which an agent can rightfully decline a challenge to her view. Suffice it to note that Riggs, too, recognizes openmindedness as an epistemic virtue but does not think that it ought to be applied all of the time.

Let us now consider a parallel argument in the argumentational context. Despite holding that open-mindedness is an important critical virtue, one can still acknowledge conditions under which it should not be applied. In line 
with Baehr's viewpoint, an agent can reasonably refuse to be open-minded when she does not believe that being so can help her, say, reach any of the argumentational goals on Cohen's list (e.g., a deepened understanding of one's position or an opponent's, or a better grasp of conceptual connections). In fact, as suggested in the previous section, in certain contexts, open-mindedness may even turn into an argumentational vice. For instance, an agent may not only fail to gain a deepened understanding of her opponent's position, but may even come out of the argument more confused about it. But the fact remains that exceptions like this do not repudiate open-mindedness as an important critical virtue but simply indicate that this virtue is not applicable all of the time. In a similar vein, then, even in conditions and contexts where open-mindedness is not called for, its status and importance as an epistemic virtue remain fully intact.

So far, I have argued that Cohen's claim that openmindedness is not always an epistemic virtue can be disputed. Moreover, I have shown that there is a need to clarify the nature of open-mindedness. How then should we construe the character trait? Specifically, how should we define open-mindedness such that it remains an argumentational virtue and can be an epistemic virtue at the same time? As mentioned, one conclusion that can be drawn from the foregoing discussion is that a working view of open-mindedness needs to be carefully circumscribed. Some recent views of open-mindedness in virtue epistemology are helpful, but are developed with specific theoretical desiderata in mind. The discussion below will bypass those aspects that are not pertinent to our concern. My primary aim is to extract from them considerations that will enhance our understanding of open-mindedness as both a critical and an epistemic virtue.

Let us begin with Wayne Riggs's theory. According to him, to be open-minded is "to be aware of one's fallibility as a believer, and to be willing to acknowledge the possibility that anytime one believes something, it is possible that one is wrong" (180, his italics). This is why when an open-minded person encounters a challenge, he is willing to "[respond] by (at least sometimes) taking such a challenge seriously" (ibid). ${ }^{9}$ Her fallibilism explains why she is willing to take challenges to her views seriously, even when she holds these views with strong conviction. We can conclude from Riggs's argument that an open-minded person takes challenges seriously. This formulation incorporates the requirement of the character trait and is an improvement over the textbook definition and Hare's, for it limits the range of activity associated with open-mindedness. It merely emphasizes what an agent is disposed to do

\footnotetext{
9 Riggs uses the qualifier 'at least sometimes' because as mentioned above, he does not think that we should always be open-minded.
}

upon encountering a challenge and refrains from specifying the subsequent courses of cognitive activities.

As Riggs's theory stands, however, it needs to be modified. Notice that Riggs's definition is concerned primarily with cases of open-mindedness in which one's views are under direct challenge. But as other theorists have pointed out, there are cases of open-mindedness that do not involve any such challenge. For example, Baehr raises the example of a judge who has to give a neutral assessment of the opening arguments at a trial. The judge's personal beliefs are not challenged, but he still has to keep an open mind in order to take both arguments seriously in weighing their relative merits. Baehr also identifies cases of open-mindedness in which agents need not perform any rational assessment. For instance, science students attempting to understand Einstein's general theory of relativity may find it necessary to 'open up' their minds in order to grasp a radical way of thinking about reality. Notice that both of Baehr's examples have analogues in the argumentational context, specifically in the cognitive activities associated with the goals on Cohen's list. For instance, implicit lemmas or assumptions may be brought up by a participant in order to bolster a premise or two in an argument. These may be ideas of which an arguer has never heard, and they may not conflict with any of her existing views. Still, to understand them, she will need to open up her mind. Also, an arguer, especially understood in the broad terms intended by Cohen and by Aberdein, may find herself at a juncture in a dispute with multiple participants where she has to adjudicate between competing views. In order to be fair and impartial, she will have to be willing to "listen to both sides of an issue, to follow the arguments or evidence where they lead, and to refrain from bringing the inquiry to a hasty or premature conclusion" (Baehr 2011, 200).

Riggs's requirement, therefore, needs to be able to accommodate these additional cases. How might it be improved? Here, it is useful to consider the definition proposed by Baehr, who is interested in uncovering the conceptual core of open-mindedness with the above examples. His description below is instructive: "An openminded person is characteristically (a) willing and (within limits) able (b) to transcend a default cognitive standpoint (c) in order to take up or take seriously the merits of (d) a distinct cognitive standpoint" (202). For Baehr, (b) constitutes the conceptual core of open-mindedness. All of the agents in the cited examples-the believer, the judge, and the science students-are considered open-minded precisely because they are willing and able to set aside, to suspend, or to loosen their grip on their usual ways of thinking when they encounter a novel standpoint. Baehr's definition is an improvement over Riggs's because it asks that an agent take seriously any standpoint, regardless of 
whether it conflicts with her own views or requires rational assessment. Still, Baehr's definition is not without problems. For instance, it is not clear whether cognitive transcendence is necessary for open-mindedness. In my view, cognitive transcendence appears necessary only in cases where the standpoint expresses a deep opposition or is of such a radically different nature that an agent needs to suspend her own views in order to grapple with it. But for standpoints of a more ordinary nature, say, ones that differ in minor respects but stand in opposition to one's own, cognitive transcendence seems unnecessary in order for the agent to understand and to take them seriously. In such a case, she will still be said to be open-minded.

We now have the ingredients for an outline of a theory of open-mindedness that treats it as both an argumentational and an epistemic virtue. What we extract from Riggs's view is that open-mindedness requires one to take challenges seriously and from Baehr's, that we should expand this requirement for application to standpoints that do not require conflict resolution or rational assessment. Putting the two together, open-mindedness amounts to the idea that we should take a distinct novel standpoint seriously. To further define it, recall that someone who is openminded towards a standpoint, say, $S$, can either accept or reject it; being open-minded implies no definite course of action, much less any specific outcome, as it is a neutral cognitive state prior to the agent's eventual commitment. What this indicates is that open-mindedness serves a specific function, which can be characterized as follows: an agent is open-minded when she is willing to let $S$ into her mind and to take it seriously. This function, I would contend, is the heart of the character trait of open-mindedness. It is exercised by all of the agents in Baehr's examples. Of course, what exactly the agent will do when she takes $S$ seriously depends on what $S$ is (i.e., an idea, a deductive argument, or an inductive inference) and what the epistemic context calls for. If $\mathrm{S}$ is a deductive argument, for example, the agent will assess its validity; if $S$ is a novel idea brought in by an opponent to strengthen her premise, she will try to see how it relates to what she knows and will draw connections; if $S$ is a proposition, then she will evaluate whether it is true; and so on.

Notice that all of these ways of engaging with $S$, and the subsequent chain of intellectual activities that they respectively initiate (including the potential revision of original beliefs), will not be possible if the agent does not first let $S$ into her mind. The importance of open-mindednessthat is, what makes it an intellectual virtue-is that it serves as a gateway, so to speak, to potential argumentational, cognitive or epistemic gains. When this gateway is blocked, as in the case of someone who is closed-minded, no serious consideration will be given to $S$ and no gains, obtained. This person's reaction to novel standpoints is likely to be one of automatic rejection. When the gateway is accessible, the agent will engage novel standpoints in a manner as the context demands, with the likely prospect for intellectual gains. ${ }^{10}$ In particular, if she is motivated by the goals on Cohen's list (like a deepened understanding of something), then she will be exercising open-mindedness as a critical virtue. If she is motivated by the pursuit of truth and knowledge, then she will be exercising it as an epistemic virtue. Most likely, though, she, qua a knower and an arguer, is motivated by both kinds of goals, in which case she will be exercising it as an intellectual virtue.

Even though I have only provided a sketch of my view, its benefits, I hope, are clear: Not only can it make good Cohen's a priori intuition that open-mindedness is an intellectual (i.e., argumentational and epistemic) virtue, but it also allows an agent to be open-minded as a good arguer without sacrificing her concomitant status as a good knower.

\section{Conclusion}

This paper examines Cohen's attempt to apply virtues to argumentation theory, focusing, in particular, on his analysis of how open-mindedness can be regarded as a critical virtue. I argue that as it is presented, Cohen's analysis involves a pair of claims that generates a tension for anyone who is simultaneously an arguer and a knower (or anyone who strives to be both). I contend that the problem can be resolved once we clarify the nature of open-mindedness and recognize that virtues have application conditions. Moreover, I advance a view that construes the character trait in terms of its function. By understanding open-mindedness as a willingness to take a novel viewpoint seriously, it becomes easy to see how it can be an intellectual virtue, that is, both epistemic and critical. ${ }^{11}$

\section{References}

Aberdein A (2010) Virtue in argument. Argumentation 24:165-179 Aberdein A (2014) In defence of virtue: the legitimacy of agent-based argument appraisal. Informal Logic 34(1):77-93

Adler J (2004) Reconciling open-mindedness and belief. Theory Res Educ 2(2):127-142

\footnotetext{
10 The engagement, of course, will have to be serious and sincere. In all likelihood, the intellectual activities involved will also consist of other intellectual virtues or cognitive activities.

11 I am grateful to Anna Cremaldi, Rick Elmore, Davis Hankins, and Luke Kwong for their help and advice in writing this paper. I would also like to thank two anonymous Topoi referees for their insightful comments and suggestions.
} 
Arpaly N (2011) Open-mindedness as a moral virtue. Am Philos Q 48(1):75-85

Axtell G (1997) Recent work on virtue epistemology. Am Philos Q 34(1):1-26

Baehr J (2011) The structure of open-mindedness. Can J Philos 41(2):191-214

Baehr J (2012) The inquiring mind. Oxford University Press, Oxford

Brandom R (1994) Making it explicit. Harvard University Press, Cambridge

Cohen D (2005) Arguments that backfire. In: Hitchcock D, Farr D (eds) The uses of argument. Hamilton, OSSA, pp 58-65

Cohen D (2009) Keeping an open mind and having a sense of proportion as virtues in argumentation. Cogency 1(2):49-64
Gardner P (1996) Four anxieties and a reassurance: Hare and Mcglaughlin on being open-minded. J Philos Educ 30(2):271-276

Hare W (1979) Open-mindedness and education. McGill-Queens University Press, Montreal

Hare W (1985a) In defence of open-mindedness. McGill-Queens University Press, Montreal

Hare W (1985b) Open-mindedness in the classroom. J Philos Educ 19(2):251-259

Hare W, McLaughlin T (1998) Four anxieties about open-mindedness: reassuring Peter Gardner. J Philos Educ 32(2):283-292

McLaughlin T (1990) Peter Gardner on religious upbringing and the liberal ideal of religious autonomy. J Philos Educ 24(1):107-125

Riggs W (2010) Open-mindedness. Metaphilosophy 41(1-2):172-188 